\title{
Exploring Knowledge Management Practices
}

\author{
Saba Sattar \\ Department of Management Sciences, The Islamia University of Bahawalpur, Pakistan \\ E-mail: saba.sattar@yahoo.com
}

Accepted: December 17, 2011 Published: February 03, 2012

Doi:10.5296/ijld.v2i1.1352ＵRL: http://dx.doi.org/10.5296/ijld.v2i1.1352

\begin{abstract}
The purpose of this study is to explore the knowledge management, how the knowledge is shared between the members of organization and to identify the different dimension of KM. This paper is qualitative in nature and author has conducted in-depth review of previous researches to formulate a conceptual framework that can help achieving the purpose of this study. Author has revealed from the discussion that in the fast revolutionized business world of today, development of KM has become the foundation of organizations. The complexity of development has been improved by expansion in the amount of knowledge available to organizations. Future research should contain of high degree of study to analytically examine the successful project knowledge management in different types of plans, companies and commences.
\end{abstract}

Keywords: Knowledge Management, Innovation, Project KM, Knowledge Outsourcing, Information Technology and Knowledge Sharing.

\section{Introduction}

Well-organized knowledge use improves competitive benefit and advances organizational success. Knowledge management (KM) has become increasingly important as organizations realize that efficient use of their enormous and diverse knowledge possessions and resources offer them with the capacity to innovate and take action to rapid varying consumer hopes. Organizations expand KM capabilities to help support a series of essential operational and innovative actions. The concentration in organizational competences has created a focus on the enlargement and accomplishment of KM processes and infrastructure necessary to hold up daily work practices.

In recent years, the importance of knowledge management (KM) has been widely documented, as the fundamentals of developed markets moved from ordinary resources to intellectual assets. The importance of KM is no longer restricted to knowledge-intensive firms in the high-tech industries. 
A common concern for researchers interested in the organizational dimension of $\mathrm{KM}$ is knowledge sharing (KS), and this has received serious awareness in current days. A complete model of intention formation in KS was proposed and tested by Bock et al. (2005).

A review of the existing literature shows the potential to improve understanding of the concept of knowledge. It is proposed here that the emergence of complexity theory indicates that the knowledge management field has reached a critical point and this provides the opportunity for new metaphors to convey the concept of knowledge, allowing better representation of its holistic and complex meaning (Barnes, 2002).

\section{Literature Review:}

Knowledge Management (KM) cooperatively and analytically restrained, accumulated, distributed, knowledge is further used to attain organizational goals and it is used to control and facilitate people, groups, business and societies (Barnes, 2002). The potential by which group of people inside the organization confine the facts that are important, continuously develop the new information, formulate that is easily assessable to the people who need it, in a very competent way so they know how to create productivity, and put in it the values as a regular factor of their job (Grant, 1996).

$\mathrm{KM}$ consists of series of approaches that is used to classify, construct, symbolize and share the knowledge within an institute. KM is commonly associated with the thought of learning, it might be different from a group learning by larger emphasize on explicit information and expansion and fostering the channels through data stream (Bock et al., 2005). Knowledge is an authority and most of the organizations apprehending that control over the knowledge of domestic companies will increase competitive advantage. Achievement of KM system is increasing day by day, and 50 percent of the corporations have implemented the KM system to enhance their productivity (Teng \& Song, 2011). Knowledge management is basically is about giving information to the right individual at the right point of time. It is not difficult as seen, but it entails a powerful knot to commercial tactic, realizing where and in what forms data survive, outline processes that span managerial purpose, and make sure that staff member of firm are agreed or support the proposals (Bock et al., 2005). Knowledge management might be counting new records, or it may exclusively focus on knowledge sharing, storage, and improvement (Van Winkelen \& McKenzie, 2007).

It is important to keep in mind that knowledge management is not about managing facts the aim is to advance, and filter the capabilities and achieve organizational ambition and objectives. Realizing KM has numerous aspects including:

- Organizational aspect: The exact methods, settings, traditions, and structure.

- Managerial aspect: The right management, policies

- Technological aspect: The right arrangement, means, and machinery accurately execute

- Political aspect: The support to apply and maintain program that include all functions of organization which frequently do not have an open noticeable return on investment (Teng \& Song, 2011).

The materialization of KM based on the economy in which importance has been transfer from conventional factor of production land, labor and capital to knowledge and agrees with the 
development of worldwide awareness (Jasimuddin, 2008). Similarly Drucker (1992) recommends the traditional factors are becoming less important to knowledge as the most important resource for the economy. Many researchers argued that successful KM is becoming an important component for all firms to make certain and prolong competitive edge. The information focuses society opening the way of data with a variety of skillfulness and competence (Davenport \& Bibby, 1999).

Professional knowledge is use to develop competitive gain and improve the managerial accomplishment. Many unions expand KM abilities to facilitate support the variety of critical operational and pioneering actions. The awareness in executive potential based on the enlargement and achievement of KM procedure and need communication, transportation roads and rail network to sustain the work performed on daily basis (Sandhawalia \& Dalcher, 2010). To get the competitive advantage it is not necessary to have capital and property, a flourishing business must have well built KM skills that facilitates firms to compete with market circumstances and maintain competitive benefit (Nielsen, 2006).

The methods and procedures underlying the progress of KM competences are not fully understood because information is blurry and chaotic and procedures must be mutual and dynamic (Sandhawalia \& Dalcher, 2010). As a result many studies advances the thoughts of $\mathrm{KM}$ interaction and courses of competences that offer logical and organized data to hold up the routine tasks of groups. Consequently a KM potential outline is necessary for general thoughts and present guidelines of how to execute a KM program (Benner \& Tushman, 2003). According to Siddique, et al. (2011) the knowledge management needs a sound academic leadership of the management and superiors that could further motivate the employees to increase organizational effectiveness.

The various studies on KM state the difference between knowledge, information, data, and wisdom, data can be measured in broader term that can be served as verified and confirm data (Wiig, 2004). The succeeding description of data, information, knowledge and wisdom try to control the general concentration on different explanation in KM:

- Data are measured to be untreated unrefined illustration of certainty (Thierauf \& Hoctor, 2006).

- Information is considered to be recorded that put into practice in a various consequential mode (Wiig, 2004).

- Knowledge is regarded as information that is progression in some significant manner (Desouza, 2005).

- Wisdom is treated as knowledge that has been process in some important approaches (Faucher et al., 2008). 


\section{Traditional knowledge pyramid:}

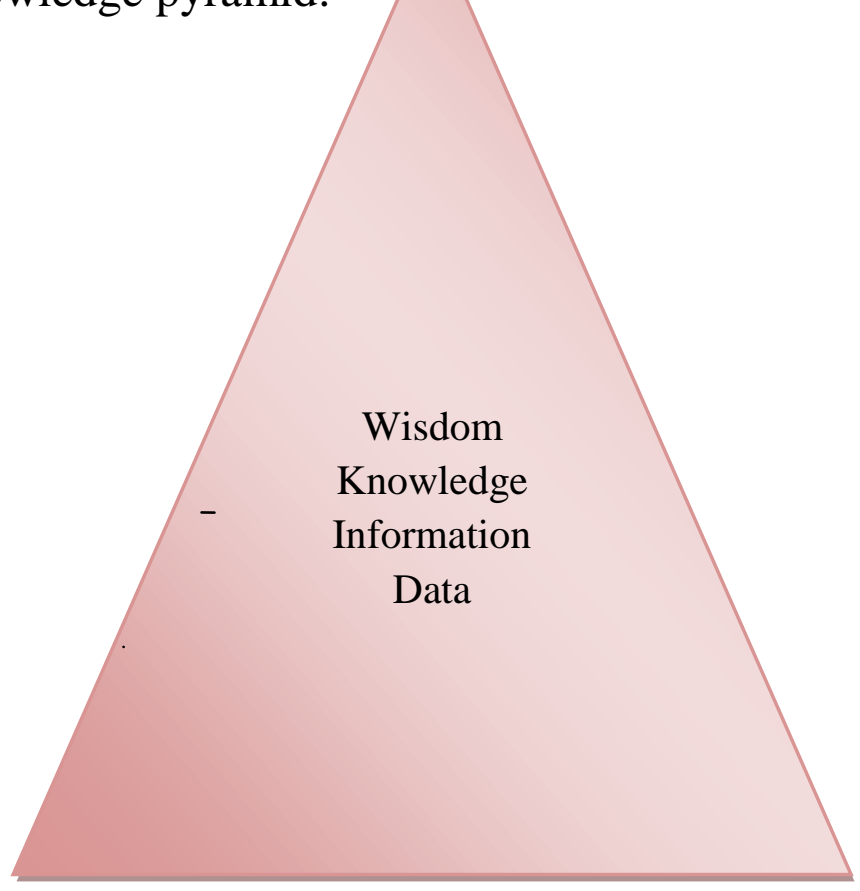

Source: Faucher et al. (2008).

According to the conventional knowledge chain of command: Wisdom is the elder expression, and data is the latest word. In a usual logic, data, information, knowledge and wisdom cannot be combined with each other. New data, information, knowledge, and wisdom are respectively included to their recognized base. Figure 1 demonstrates the traditional knowledge pyramid in which data, information, knowledge, and wisdom are perceived in different classes (Faucher $e t$ al., 2008).

In knowledge-based world business gave more importance to knowledge sharing and it is gradually important for the achievement of firms (Barrett et al., 2004). The reality is that executive success is depending upon capabilities to distribute the knowledge among all the members of organizations and to recover the abilities by incorporating new expertise. One study shows that those businesses are more successful who share large amount of information among all the division of organization as compared to those who distribute smaller amount of knowledge (Argote et al., 2000). "Project knowledge management (PKM) is knowledge management in project situations and thus the link between the principles of knowledge management and project management" (Hanisch et al., 2009). Love et al. (2005) place the origin for accepting knowledge management in mission setting. In respective area of job in KM project they put their practices in the framework of cross-functional and global project groups and in addition fulfill the responsibility of giving the instructions in project. 


\section{Macrothink

In Knowledge outsourcing make an open agreement with outside professionals to create knowledge concentrated resources that are utilized in a company for getting the core output by using less input. Knowledge outsourcing increase exterior foundations for knowledge design relatively depend on inner capacities (Lam \& Chua, 2009). K-map can be utilized as the input technique, process and instrument to successfully envision the resource, flow, control and execution of implicit and unambiguous information in the KM quarter by raising consideration of the contact between knowledge supplies and dynamics in development and institutes (Driessen et al., 2007). K-map is used to maintain knowledge draft and sketch, to extend theoretical chart as chain of commands or networking, and present particularly urbanized events to draw out and manuscript conceptual record from diverse information human resources such as specialist (Yun et al., 2011) 


\section{Macrothink $\Delta$ Institute ${ }^{\text {tm }}$}

\section{Knowledge Management Model}

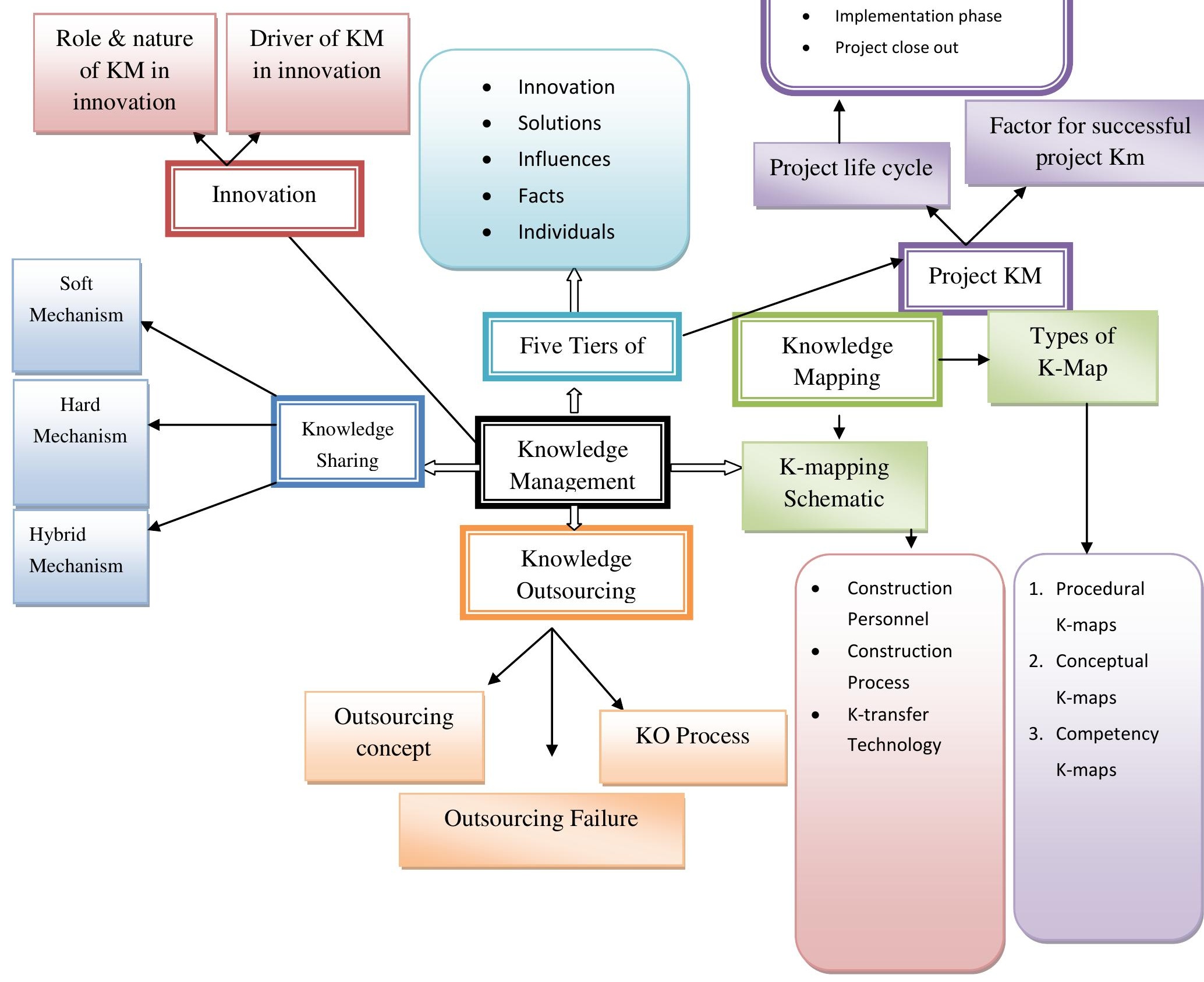




\section{Discussion}

\subsection{KNOWLEDGE SHARING}

Existing literature shows large amount of percentage that methods which are employing for the sharing of information can be categorized as two important leading clusters namely, tacit and explicit. Taking knowledge as a focal point two special means soft and hard mechanisms are used to transmit the facts. The soft method has a propensity to transfer tacit knowledge through personally interface. The hard mechanism characterizes the movement of explicit knowledge using Information and information technology like online meeting (Jasimuddin, 2008; Aslam et al., 2011). Similarly the soft mechanism approach where information is strongly attached with individuals and who share with each other by direct communication. Although in hard method data is pile up in codes and hold in a catalog from where it can simply use and review by anybody in the company (Hansen et al., 1999).

\subsubsection{Soft Mechanism}

Even though viewing the soft approach it is important to spilt the information among the personnel. According to Davenport and Prusak (1998) "firms hire smart people and let them talk to one another and use water coolers, talk rooms, and picnics as examples of places where the transfer of tacit knowledge can take place" similarly different tools are used for conveying the data. Nonaka \& Takeuchi (1995) use " examples of apprenticeships, brainstorming camps, the use of metaphors and analogies, social network, and learning by doing as viable ways of tacit knowledge transfer". Corresponding to this Argote et al. (2000) classify additional devices that subsist for transmitting knowledge and to incorporate instructing members, permitting them to monitor the routine work of other specialist, and giving chances for communication connecting managerial associate.

\subsubsection{Hard Mechanism}

It is recommended by many researchers that information technology plays an important role in broadcasting the information in the society. It makes much easier to transmit the knowledge. Hard mechanism has capacity to convey the huge collection data and to cut down the geographical hurdles. In many studies respondents gave importance to use e-mail as a communication channel (Bhatt, 2001). In addition to e-mail individuals pay more attention to other electronic devices like Lotus Notes, Instant Messaging and Electronic bulletin board to maintain the knowledge transfer behaviors (Sbarcea, 1998). 
Distinguishing features of the approaches to knowledge sharing

Features

Approaches to knowledge sharing

Soft

Approach

Hard Approach

Nature of knowledge

Tacit

Explicit

Role of technology

Insignificant

Technology focused

Role of people

Individual focused

Little

Tool

face-to-face interaction

Lotus, instant messaging etc

Source: Jasimuddin (2008)

The above table shows the different features of hard and soft approach in transferring the knowledge in business.

\subsubsection{Hybrid Approach}

Some studies show that applicants use mixture of both soft and hard approaches. That's information shifting might be begin with oral participation and end up with official remarks. A winning hybrid policy is one that obtains benefit of the positive characteristic of both the soft and hard instruments. By means of this planned mechanism companies could first use the soft technique to get the information from personnel and then use explicit technique to store that information in a record (Jasimuddin, 2008).

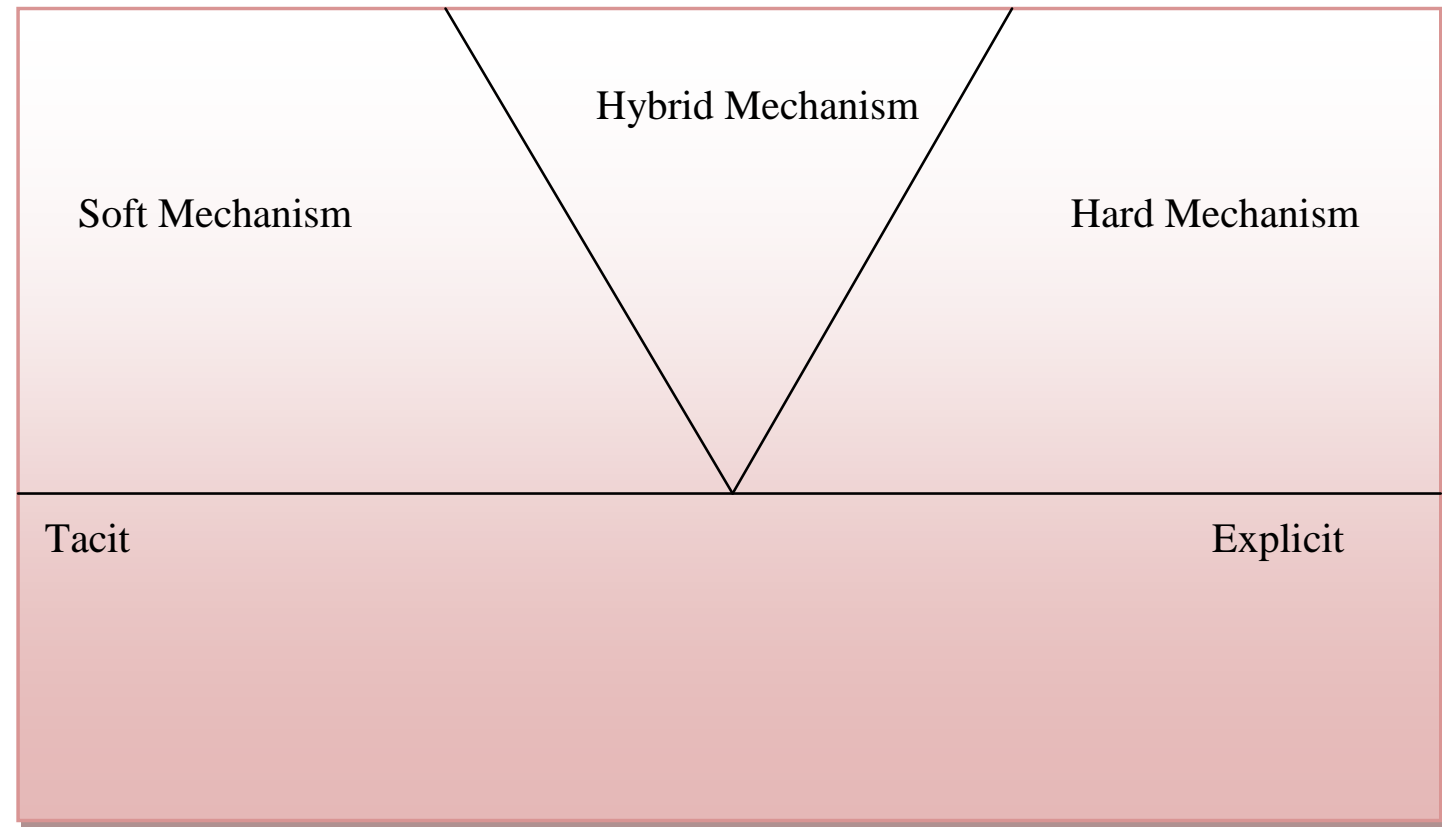




\subsection{INNOVATION}

Innovation is defined as the new arrangement of fundamental aspects of invention and bring new intervention into the creation organism. Innovation introduces the new skills, tools and new manufacturer product to fulfill the need of consumers. It entails the latest item for consumption, the modern technology, the innovative marketplace (Chen et al., 2004). Similarly, in merchandise enlargement schedule innovation process include the scientific, objective, and comprehension base actions (Cardinal et al., 2001).

From the literature it is observed that innovation is supported by KM that consist creation of new thoughts and proper utilization of organizational resources. KM also comprises the expertise to use proper capital, at what time, where and when it is necessary (Parlby \& Taylor, 2000). KM is a deliberate arrangement to increase talent of business, enlarge the swiftness and usefulness in distributing goods or services for the customer benefits, to handle the establishment, distribution and collection the information of company's profit. KM is not exclusively paying attention on innovation but it builds up favorable atmosphere for the innovation to take place (Plessis, 2007).

\subsubsection{Nature and Role of KM in Innovation}

The first important role that innovation plays in KM is facilitating the transfer of data and codification of implied information. Tacit knowledge is significant for institutions to attain the capability of innovations. The companies that are strongly innovative learn more and more and make it complex for challenger in the market and also compounding it so it cannot be duplicated (Plessis, 2007).

The second important role in innovation is linked with explicit knowledge. Tacit knowledge play more important role as compared to explicit in the process of innovation. Because in explicit it is convenient for opponent to capture the market. In research and development the attributes of explicit knowledge are powerful with wealthy substitute of tacit knowledge. It is essential for unions to assemble assets and facilities that will permit them to confine and codify knowledge and product development practices, to make certain knowledge transfer (Cardinal et al., 2001).

The third important role is cooperate in innovation is to allow the teamwork. Cooperation, both in-house and outdoor to the groups, takes part in sharing of knowledge and put together combined knowledge. Larger will be the effort of group member higher will be the transfer of tacit knowledge. The information that is collected by all group members decrease threat and expenses in innovation process (Cavusgil et al., 2003).

The fourth important role of innovation in $\mathrm{KM}$ is running different trials in $\mathrm{KM}$ lifecycle which involve following stages designing, assembling, and distributing the data. KM makes sure that information is that is essential in innovation process is existing and reachable. Many firms use knowledge management activities and techniques, such as environmental inspection, benchmarking, intranets, firm-wide databases and communities to acquire knowledge and to make it available (Plessis, 2007). 


\section{N Macrothink Institute ${ }^{\mathrm{TM}}$

\subsubsection{Drivers of KM in Innovation}

From the previous studies three main drivers of KM in the process of innovation are important The first fundamental driver in market is to generate, assemble and sustain the competitive edge by consumption of data that is gathered by association of group attempts. In today's setting it is difficult to challenge the applicants because consumer requirements are varying, technology modification, and wide aggressive demands (Cavusgil et al., 2003).

The second driver is capital that is used to lessen complication in the innovation course and maintain the resources in a way that effectiveness and efficiency of process raised (Plessis, 2007). Cavusgil et al. (2003) concur that KM is a process by which density of innovation is measured. Creation of innovation system is determined by synergy effect and supervision of knowledge. It help to administer the foundation of latest facts during the innovation process, but also indirect access of knowledge as a resource used as input to the innovation process.

The third driver of applying knowledge management to the benefit of the innovation process is the assimilation of information both internal and external to the business; as a result make it more easily reachable and available. Knowledge assimilation entails that timely insight can be readily available at the suitable occasion for good judgment. Knowledge can be swapped, shared, developed, polished and made available when it is required. Knowledge addition through knowledge management stages, tools and course should therefore assist discussion to let the individual and executive learning and modernization (Chen et al., 2004).

\subsection{FIVE TIRES OF KM}

The five tires of KM is used to assess KM hard exertion, catalogs of data resources, correct the misunderstandings, gave importance to KM life cycle that gave direction to administrator and executives, map and direct the progress of resources of information in an organization. It is also used to review intensity of KM effort in a business. The strength of KM attempt can be measured by calculating the data accounts and metrics (Hicks, 2006)

The five tires of KM include individual, facts, solution, and innovation. As there is substantial discussion over the definitions of the terms data, information, and knowledge so here several opinion plainly differentiate the set of definition of five tires.

1. Individual knowledge is defined as "knowledge contained only in the mind of a person."

2. Facts are defined as "atomic attribute values about the domain."

3. Influences are defined as "data in context that has been processed and/or prepared for presentation."

4. Solutions are defined as "clear instructions and authority to perform a task."

5. Innovation is defined as "the exploitation of knowledge-based resources" (Hicks, 2006). 


\section{Five tires of KM}

INNOVATION

SOLUTIONS

INFLUENCES

FACTS

INDIVIDUALS

Source: Hicks (2006).

command the reason is that the one main objective of KM is to share the information among the employees working in an organization. This tire is the foundation of ladder that supports the other tires of KM (Hicks, 2006).

\subsubsection{Fact Tire}

The function of this tire is to give the unprocessed data to upper stages of KM tires. The company's codified data consist of manuscripts which are explained in next level of KM tire and hold the records in fact tire. Data stock rooms and discussion centre are building and their objective is building the power for management decision at the same time operational records consist of easily available details about the firms. Several software plans pay attention on the investigation of data quarters in catalogs (Hicks, 2006).

\subsubsection{Influence Tire}

The task of this tire is to help the individuals in decision making. Influence is classify as incorporated facts and set in a framework after the complete arrangements. At this stage facts are developed by a system that is called decision support system (DSS). This tire include three 
subcategorize computer-assisted decision making, cooperative influence creation, and computer assisted influence dissemination (Hicks, 2006).

There are three main types of computer-assisted decision making systems: learning systems, DSS, and reports. Learning organism are pool of workstation software appliance that may be used create solutions or influences through analysis of data with no creature involvement. DSS use a static set of mold that examine limited information. The second subclass of the influence tier is cooperative influence creation. Knowledge collection and groupware are included in circumstance; assist the designing of clarification and control. The third subclass of the influence tier, computer-assisted dissemination of influence, contains three subprograms. They are "Yellow Pages" that place human being include individual influence or solutions, text management systems that situate and exhibit papers by context (Hicks, 2006).

\subsubsection{Solution Tire}

The responsibility of the solution tier is to formulate choice and implement them. The solution tier is defined as "shareable source that contains a complete solution for a specific task and the authority to act". It gave total and complete results for proper decision making. Professional system is the best example of because this practices include all the information that is essential for execute the general data, problem solving and compose and implement the decision. Another sub classification of solution tire is best practices it describes the complete explanation of business and make sure that solution is comprehensive and established (Hicks, 2006).

\subsubsection{Innovation Tire}

Innovation occurs when knowledge from any tier is joint with tactic, helping a methods of reengineering, rising commercial effectiveness, growing company efficiency, or generating awareness based commodities or services. As defined by Edvinsson et al. (2004) innovation = (reuse + invention) $*$ exploitation. Innovation might be the conclusion of assimilation of resources beginning from many tires. One best example is Visa, uses neural networks from the influences tier for fraud detection (Turban et al., 2001). The innovation tier and individual tier are very strongly linked to the academic dexterity and ability sections. Examples of intellectual agility include advance, imitation, adaptation, and packaging (Roos et al., 1997).

\subsection{PROJECT KM}

Project knowledge management (PKM) is knowledge management in project situations and thus the link between the principles of knowledge management and project management (Love et al., 2005). Project KM not only focus the information surrounded by project but also take consideration among the diverse project and information regarding project (Schindler, 2002). Information bounded by the project is directly allied with the styles and communication methods in project. Both are highly reliant on project director and the manner of personnel project management. Knowledge regarding development symbolizes an impression of the project countryside in an association. The knowledge transmits starting and among plans can be referred to as proficient knowledge, practical knowledge, technical knowledge, and skill base knowledge. In the figure it is shown that how KM work in a project settings (Hanisch, 2009). 


\section{Knowledge Management in a Project environment}
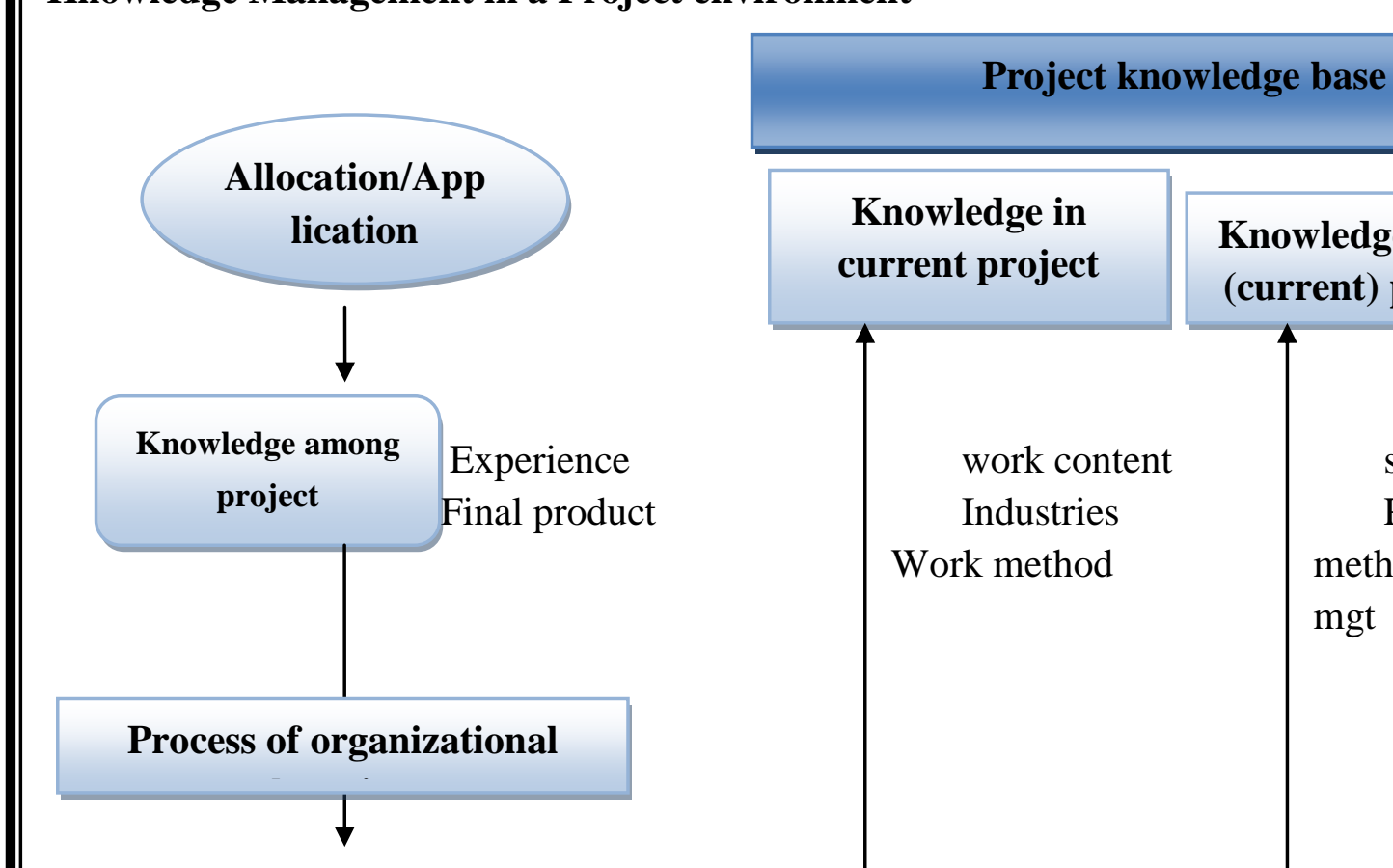

\section{Organizational knowledge base}

\subsubsection{Project life cycle}

The project executive and project group have one common purpose: to bring out the exertion of the project for the intention of meeting the project's goals. Every project has early stages, a middle phase during which activities move the project toward completion, and an ending stage at which project is completed. A normal project normally has four major phases' initiation, planning, implementation, and close out (Schindler \& Eppler, 2003). 


\section{Macrothink

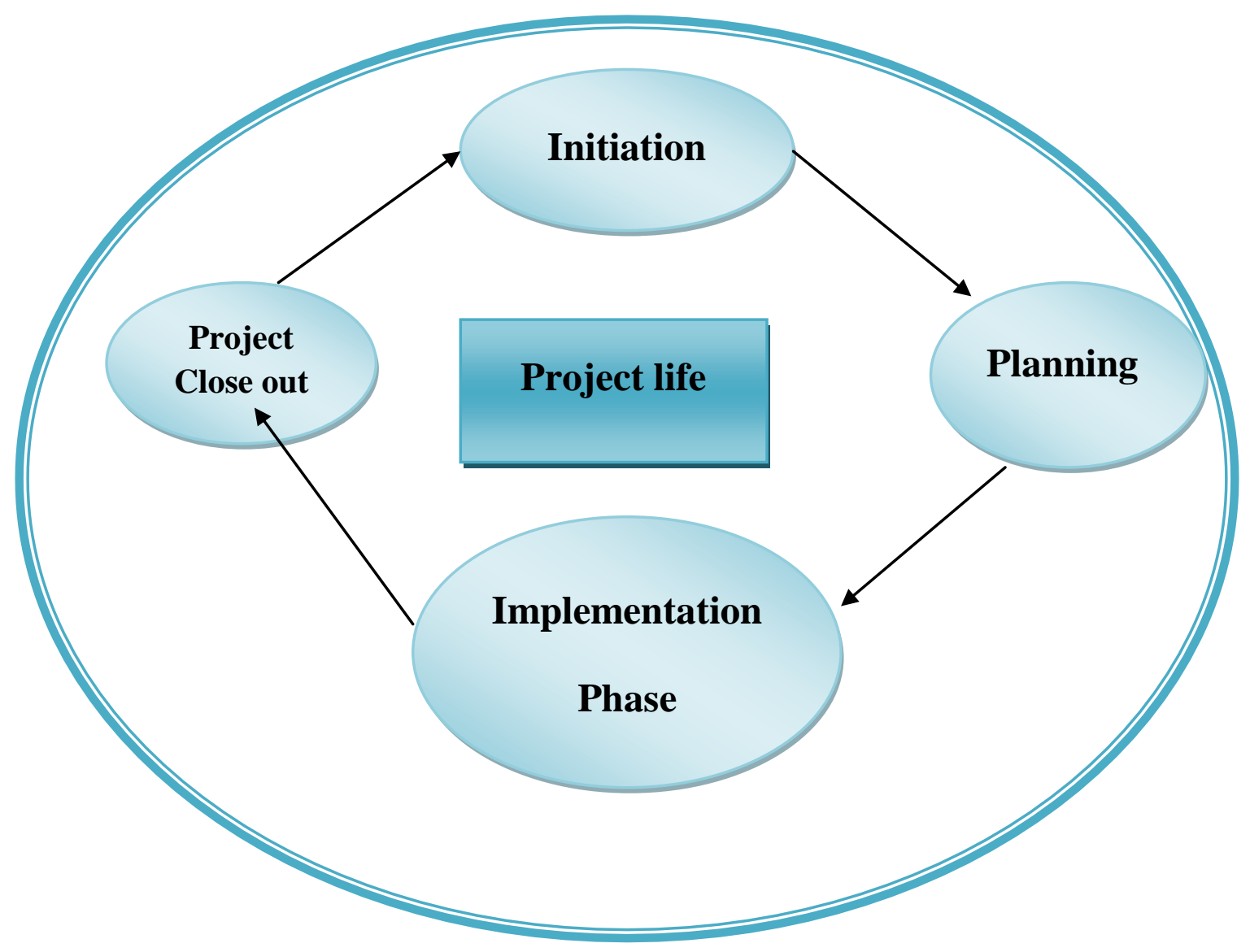

\section{Initiation phase}

At this stage the aim or need is identified it might be a business trouble or prospect. The project objective or need is identified; this can be a business trouble or prospect. A suitable answer to the requirements is known in a business case suggested with proper solutions. A practicability study is carrying out to examine whether each choice tackle the project problem. The suggested clarification is accepted, a project is starting to deliver the standard explanation and a project boss is selected (Hanisch, 2009).

\section{Planning phase}

The next phase, the planning phase, is where the project solution is further developed in as much detail as possible and plans the steps necessary to meet the project's objective. In this step, work is allocated to the teams. The project's tasks and resource necessities are recognized, beside with the policies and procedures. A project plan outlines the actions, responsibilities, addiction and timeframes. The project manager organizes the financial plan of project; by providing fees approximation for the employment, tools and equipment expenses. The plan is used to screen and manage expenditure expenditures during project implementation (Hanisch, 2009). 


\section{Implantation phase}

During the third phase, the project plan is put into movement and achieves the objectives of the project. It is essential to sustain power and communicate as desirable at some stage in implementation. Development is constantly monitored and proper alterations are made and documented. In any plan a project executive will spend most of their time in this step. During project implementation, groups are assigning the specific tasks and check the progress on regular basis. The project manager exercises the knowledge to preserve control over the course of project. Manager compares the actual performance with desired performance and if there is any gap fulfills it (Hanisch, 2009).

\section{Project close out}

This is the final phase if project life cycle at this stage goods and services are ready to deliver to the clients, hand over plan documents to the company, come to an end with contractor, liberating project capital and communicate the conclusion of the project to all stakeholders. Examine the intelligence of knowledge is transmitted back to the project organization, which will facilitate upcoming project teams (Hanisch, 2009)

\subsubsection{Factors for successful project KM}

In one study expert interview determine the four categorize of success factor of KM project namely

1. information- and communication technology;

2. Organization;

3. Methods; and

4. Culture and communication (Hicks, 2006).

The part of information and communication technology simply provide as support to victorious project KM. It is complex for companies to put in use of developmental KM exclusive focusing on techniques of information technology and achievement of software must not be judged as ending point time to time examination is necessary. The next area is the organization that gave importance to personnel and reorganization of tools that are used so the primary aim is the enlargement of software management practices in which the utilization of tools is incorporated. In relation to organization basic guideline from higher level management is necessary to entrench the project KM in business (Hicks, 2006).

The use of a standardized project knowledge management method put forward broad situation and schedules to human resources. Some time it is not possible to use all practicable tools so one individual in a corporation take the responsibility to pass the information at all level of company, implement the proper methods and find out the problems that occur in a system. So the chosen individual is an orientation for all achievable thoughts, queries and proposal and in addition drives each issue in a business. A sympathetic corporate culture is very important factor for the exchange of data among the team that are working across the geographical boundaries. Cooperation of outside parties is also beneficial for the organization. To increase the value of project KM flexible component such as cooperation, honesty and faith encourage the project KM (Hicks, 2006). 


\subsection{KNOWLEDGE MAPPING}

Knowledge mapping is a process by which organizations can recognize and classify knowledge resources inside the organization like citizens, practices, content, and technology. It allocates an organization to completely control the existing knowledge in the organization, as well as classify hurdles and limitation to fulfilling planned goals and objectives. It is constructing a roadmap to locate the information needed to make the best use of resources (Yun et al., 2011). While Tiwana (2002) emphasize that a K-map is used to build up theoretical charts as hierarchy or network, support knowledge script and report, and present strongly developed methods to draw and manuscript the conceptual models from variety of information sources like professionals.

\subsubsection{Types of K-maps}

There are several types of knowledge mapping that have been developed from various aspects of organizations and projects. The first category of K-map is “process-based K-map". It utilizes the picture of information and possession of data in the process and mission of company (Liu \& $\mathrm{Hsu}$, 2004). The second form of knowledge mapping is "conceptual K-maps" it is used for managing the content of data and handling and categorizes the information according to the company's chain of command (Caldwell, 2002). Third category is "competency K-maps" it focuses on the documentation of capabilities, practice, arrangement, work familiarity and career development of several personnel like quality designer, project supervisor, sales manager, and finance manager record their skills and handle them in a file (Bish, 1999). There are some other types of k-mapping that are used in organization that are web-based K-maps, strategy-based K-maps and cognitive K-maps (Yun et al., 2011).

\subsubsection{K-Mapping Schematic}

As it is discussed that k-mapping is use to recognize the connection among data storage and development of business. On the basis of k-mapping graphical representation of information is used for the project. This K-mapping schematic can be used to create the policy for support $\mathrm{K}$-maps to production of project organizations. This figure shows the different variables of schematic (Yun et al., 2011). 


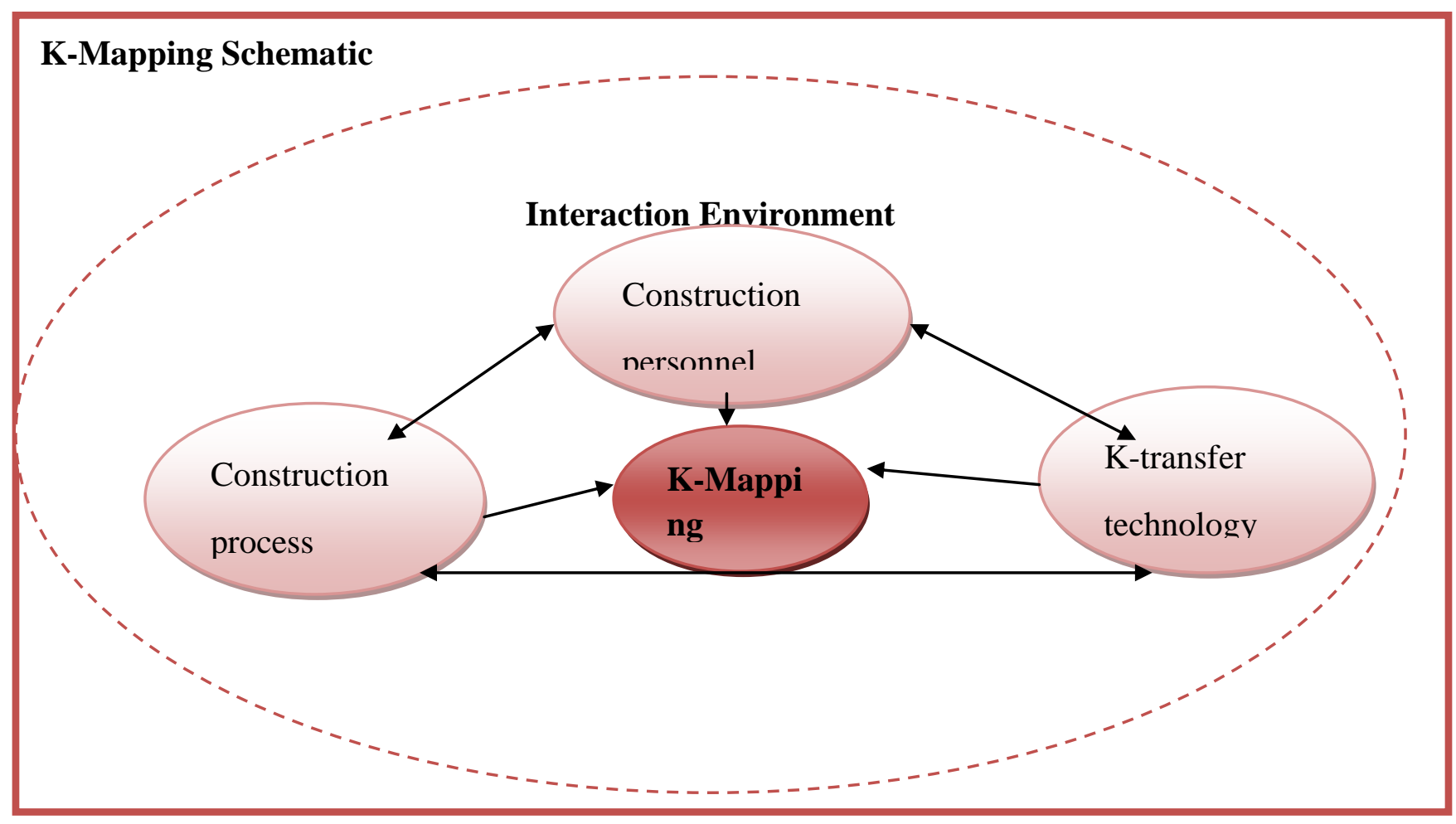

Interaction environment is similar to the building of organizational plans in which diverse individual, methods and various information technologies with different data foundations, resources and flow of facts are exchange and work with new tools and systems in the surroundings (Yun et al., 2011).

\section{Construction personnel}

Information is developed, process, and used in projects of company so individuals are accept as a input in k-mapping. In addition all the plans are executed by construction personnel who work with employees who are working on plans and supervisor (Fryer, 2004).

\section{Construction process}

This process is judged as a complex method for all the plans of organization. Each plan consists of several courses and sub categorizes that is considered as a basic component for project management (Tzortzopoulos et al., 2005).

\section{K-transfer technology}

K-transfer tools are used in K-mapping because computer and internet technology make the project effective. By using these latest technologies time is saved and cost is decreased and organizations easily achieve the goals (Koch, 2003).

\subsection{KNOWLEDGE OUTSOURCING}

Knowledge process outsourcing (KPO) is a form of outsourcing, in which knowledge linked and information allied effort is carried out by workers in a different group or by a contributory of the same group, which may be in the same country or in an offshore location to accumulate expenditure (McKeen et al., 2002). Similarly, Knowledge Process Outsourcing (KPO) is the outsourcing of high-end business functions carried out by expert personnel. KPO firms provide 
knowledge in the processes they carry out and often make low level business assessment (Sommer, 2003),

\subsubsection{Outsourcing concept}

The idea of knowledge outsourcing (KO) latest to the KM. outsourcing is a operational dealing which engage in making the agreement with outside companies with advertising and purchasing business resources. Several types of outsourcing are used like system expansion; business process; utility computing and service provision (Ross \& Westerman, 2004). Most of the studies encourage the business to subcontract. Outsourcing describe various variable which consist of calculated importance of IT and the procedure, in which IT is applied to the company (Lam \& Chua, 2009)

\subsubsection{KO process}

The process of KO consists of five steps. The first step is to identify the information need. In this step firstly discover the need of customer. The basic information need include the life and sort knowledge material goods required. These knowledge requirements should be precise and intended to solve particular problems. The next step is knowledge sourcing. At this phase various resources are regarded to the customer so that data want must be fulfilled. This step contains the classification and estimation of potential information supplier, who may perhaps be persons or corporation. The third step is knowledge service negotiation. At this point cooperation of knowledge services among the consumer and the knowledge contributor. If negotiations are victorious then as a result an agreement is made between the customer and the information donor. Such agreement consist of agenda of at what time knowledge resources are to be distributed, expenses and bill, and certificate and intellectual goods planning (Lam \& Chua, 2009)

The next step is knowledge delivery include transmit of data from knowledge distributor to consumer. Information can be delivered in many ways one means is manufacturing of papers that detain knowledge possessions. The value of knowledge services is examine by a similar process ensure the correctness of knowledge release and the feature of the knowledge assets, in agreement with what was initially settled and agreement describe. The last and final step is knowledge utilization in which it is observed that the assets that are supplied by provider are consumed by the consumer (Lam \& Chua, 2009).

\section{Model of KO process}

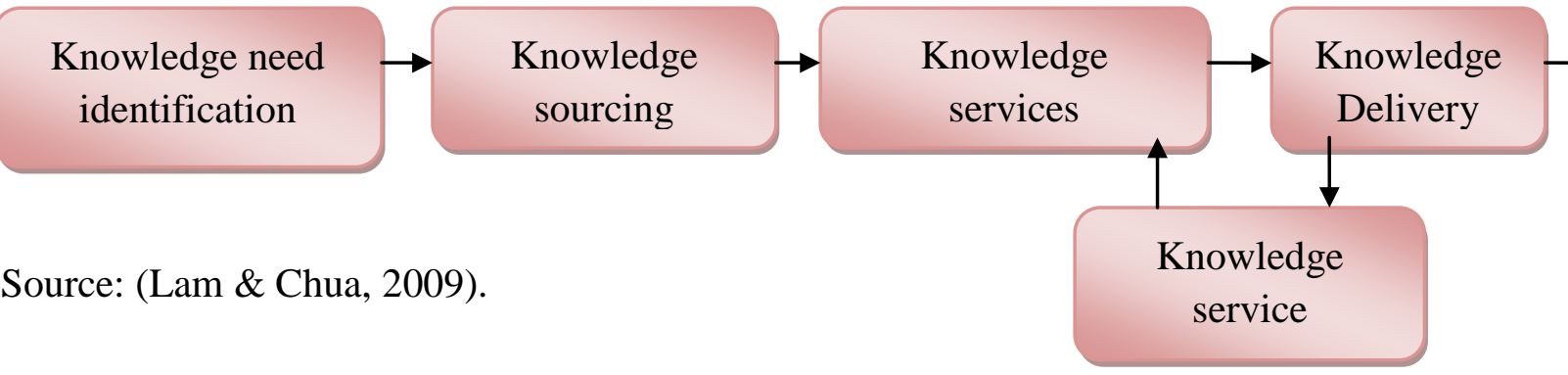
Knowledge utilization




\section{Macrothink

\subsubsection{Reasons of Outsourcing failure}

Earl (1996) classify following sorts of outsourcing danger:

1. Chances of feeble administration;

2. Untrained employees

3. Industry insecurity;

4. Old-fashioned technology expertise;

5. Common doubt;

6. Unseen expenditure;

7. Not having of organizational learning;

8. Failure of inventive abilities;

9. Risk of a timeless triangle;

10. Technical invisibility;

11. Unclear focus.

Additionally Barthelemys (2001) have observed the unseen cost to four key phases of outsourcing

1. Wholesaler exploration and agreement

2. Changing to the dealer;

3. Managing the attempt; and

4. Conversion after outsourcing.

\section{Findings}

The results of the analysis of this research provide extra support that organizations must enlarge capabilities to sustain and make easy interaction and feedback to ensure the flow of information. Organizations need to take steps to bring together persons with general interests and advance their chances of achievement in knowledge sharing. Support and facilitation of society of practice are optimistic step towards successful KM, especially within a distributed organization. Knowledge management is not simply about recording and influencing explicit knowledge, but needs to address that which is implicit, and as a result from which advantage can be consequent only through process rather than content.

This paper also find different dimension of KM like project KM, knowledge-Mapping, information inside projects is directly associated to the plan techniques and the communication practices in projects. Consequently, four types of K-mapping structure for building project organizations were drained from the literature. These four present the criteria to classify the suitable category of K-map for creation project organizations, according to the features and circumstances of their own construction personnel, construction processes, and K-transfer technologies.

The findings of this research and the framework presented within, have implications for KM practice. The research established that KM initiatives evolve from the initial knowledge requirements, to a state of continued growth of knowledge use within organizations. In this state, knowledge processes need to be embedded in the daily routines of organizations and supported by knowledge infrastructure. 


\section{Conclusion}

This paper demonstrates the conclusion of an explorative study on KM. Societies try to find to gain new competencies in order to achieve efficiency. This paper deals with knowledge sharing medium to expand our consideration of the plan that assure to be most suitable in the new knowledge market. The study discloses that a hybrid strategy allows organizations to search for an incorporated approach to knowledge transfer through the interaction between soft and hard mechanisms. This general limitation in business practice is outstanding regarding the high prospective settlements concerning efficiency, effectiveness and innovation consequential from effectively executed Project KM in multiple types of companies. In this study it has also explored and planned four types of K-mapping model for project presentation and development from the outlook of creation of project organizations. For flourishing implementation of K-maps in construction project organizations, the K-maps should be deliberately developed, thinking the K-mapping mechanism determined based on the organizational wants.

This paper also categorizes knowledge into five tiers of KM: individual, facts, influences solutions, and innovation. The five tires KM comprise all of the kinds of KM known in the literature, endow with a means for assessing the KM effort in a firm, make out the contact between information resources, and give way to confrontation for KM efforts inside the business. Based on this study, it is clear that knowledge management plays an important role in innovation. Further investigation is essential, but, on the possible role of knowledge management in innovation and how the value of knowledge management can be maximized to ensure a more efficient and effective innovation process. 


\section{References}

Argote, L., Ingram, ,. P., Levine, ,. J., \& Moreland, ,. L. (2000). Knowledge transfer in organisations: learning from the experience of others" . Organisational Behaviour and Human Decision Processes, 82(1), 1-8.

Aslam, H. D., Javed, T., Tanveer, A., \& Khan, M. (2011). A Journey from Individual to Organizational Learning (Exploring the Linking Bridge). International Journal of Academic Research, 3 (3), 738-745.

Barnes, S. (2002). Knowledge management system theory and practices. London: Thomson Learning. Barrett, M., Cappleman, ,. S., Shoib, ,. G., \& Walsham, ,. G. (2004). "Communities: managing technology and context', , European Management Journal , 22(1), 1-11.

Barthelemy, J. (2001). "The hidden costs of IT outsourcing. Sloan Management Review , 42(3), 60-9.

Benner, M., \& Tushman, ,. M. (2003). Exploitation, exploration, and process management: the productivity dilemma revisited" . Academy of Management Review, 28(2), 238-56.

Bhatt, G. (2001). "Knowledge management in organizations: examining the interaction between technologies, techniques, and people’”. Journal of Knowledge Management , 5(1), 68-75.

Bish, C. (1999). ' Building competency maps'. Journal of Knowledge Management , 7, 10-13.

Bock, G.W., Zmud, R.W., Kim, Y.G. and Lee, J.N. (2005), ' Behavioral intention formation in knowledge sharing: examining the roles of extrinsic motivators, social-psychological forces, and organizational climate', MIS Quarterly, 29 (1), 87-111.

Caldwell, F. (2002). Knowledge Management Scenario: What's Next?, Gartner US Symposium ITXPO. Orlando, FL.: Walt Disney World,.

Cardinal, L., Allessandri, ,. T., \& Turner, ,. S. (2001). “'Knowledge codifiability, resources, and science based innovation' '. Journal of Knowledge Management , 5(2), 195-204.

Cavusgil, S., Calantone, ,. R., \& Zhao, ,. Y. (2003). "Tacit knowledge transfer and firm innovation capability' '. Journal of Business \& Industrial Marketing , 18(1), 6-21.

Chen, J., Zhaohui, ,. Z., \& Xie, ,. H. (2004). Measuring intellectual capital', . Journal of Intellectual Capital , 5(1), 195-212.

Davenport, S., \& Bibby, ,. D. (1999). Rethinking a national innovation system: the small country as SME', Technology Analysis and Strategic Management, 11(3), 431-62.

Davenport, T., \& Prusak, ,. L. (1998). Working Knowledge: How Organisations Manage What They know. Boston, MA: Harvard Business School Press,.

Desouza, K. (2005). New Frontiers of Knowledge Management. New York, NY: Palgrave Macmillan. Driessen, S., Huijsen, ,. W., \& Grootveld, ,. M. (2007). "A framework for evaluating knowledge-mapping tools", ,. Journal of Knowledge Management, , 11(2), 109-17.

Drucker, P. (1992). "The new society of organisations". Harvard Business Review , 95(5), 95-105.

Earl, M. (1996). The risks of outsourcing IT', Sloan Management Review, 37(3), 26-32.

Edvinsson, L., Dvir, ,. R., Roth, ,. N., \& Pasher, ,. E. (2004). Innovations: the new unit of analysis in the knowledge era', Journal of Intellectual Capital , 6(1), 40-58.

Faucher, J.-B. P., Everett, A. M., \& Lawson, R. (2008). Reconstituting knowledge management. JOURNAL OF KNOWLEDGE MANAGEMENT, 2(3), 3-16.

Fryer, B. (2004). The Pratice of Construction Management. Oxford: Blackwell Publishing, . 
Grant, R. (1996). prospering in dnynamically-competitive environments: organizational capibility as knowledge integration . organization science, 7(4, )375-87.

Hanisch, B., Lindner, F., Mueller, A., \& Wald, A. (2009). Knowledge management in project environments. JOURNAL OF KNOWLEDGE MANAGEMENT , 13(4), 148-160.

Hansen, M., Nohria, ,. N., \& Tierney, ,. T. (1999). What's your strategy for managing knowledge?'. Harvard Business Review, , 77(2), 106-16.

Hicks, R. C., Dattero, R., \& Galup, S. D. (2006). The five-tier knowledge management hierarchy. JOURNAL OF KNOWLEDGE MANAGEMENT , 10(1), 19-31.

Jasimuddin, S. M. (2008). A holistic view of knowledge management strategy. JOURNAL OF KNOWLEDGE MANAGEMENT , 12(2), 57-66.

Lam, W., \& Chua, A. Y. (2009). Knowledge outsourcing: an alternative strategy for knowledge management. JOURNAL OF KNOWLEDGE MANAGEMENT , 13(3), 28-43.

Liu, D., \& Hsu, ,. C. (2004). "Project-based knowledge maps: combining project mining and XML-enabled topic maps'. Internet Research , 14(3), 254-66.

Love, P., Fong, ,. P., \& Irani, ,. Z. (2005). Management of Knowledge in Project Environments. Oxford: Elsevier.

McKeen, J., Smith, ,. H., Joglekar, ,. N., \& Balasubramanian, P. P. (2002). 'Developments in practice v:IT sourcing: building, buy or market', ,. Communications of the AIS, , 9, 120-35.

Nielsen, A. (2006). "Understanding dynamic capabilities through knowledge management. journal of Knowledge Management, 10(4), 59-71.

Nonaka, I., \& Takeuchi, ,. H. (1995). The Knowledge Creating Company. Oxford: Oxford University Press.

Plessis, M. d. (2007). The role of knowledge management in innovation. JOURNAL OF KNOWLEDGE MANAGEMENT , 11(4), 20-29.

Roos, J., Roos, ,. G., Dragonetti, ,. N., \& Edvinsson, ,. L. (1997). Intellectual Capital: Navigating in the New Business Landscape. Basingtoke: Macmillan, .

Ross, J., \& Westerman, ,. G. (2004). "Preparing for utility computing: the role of IT architecture and relationship management”, . IBM Systems Journal, , 43(1), 5-19.

Sandhawalia, B. S., \& Dalcher, D. (2011). Developing knowledge management capabilities: a structured approach. JOURNAL OF KNOWLEDGE MANAGEMENT , 15(2), 313-328.

Sbarcea, K. (1998). "Know what, know how, know why: implementing a knowledge management system - the Philips Fox experience". Australian Law Librarian , 6, 4-8.

Schindler, M. (2002). Wissensmanagement in der Projektabwicklung. Lohmar-Koln: Josef Eul Verlag $\mathrm{GmbH}$.

Schindler, M., \& Eppler, ,. M. (2003). "Harvesting project knowledge: a review of project learning methods and success factors". International Journal of Project Management, 21(3), 219-28.

Siddique, A., Asalam. H. D., Khan, M., \& Fatima, A. (2011). Impact of Academic Leadership on Faculty's Motivation, and Organizational Effectiveness in Higher Education System. International Journal of Business and Social Sciences , 2 (8), 84-91.

Sommer, R. (2003). 'Business process flexibility: a driver for outsourcing”. Industrial Management \& Data Systems , 103(3), 177-83. 


\section{Macrothink

Teng, J. T., \& Song, S. (2011). An exploratory examination of knowledgesharing behaviors: solicited and voluntary. JOURNAL OF KNOWLEDGE MANAGEMENT , 15(1 ), 104-117.

Thierauf, R., \& Hoctor, ,. J. (2006). Optimal Knowledge Management,. Hershey, PA.: Idea Group, . Tiwana, A. (2002). The Knowledge Management Toolkit,. London: Prentice Hall PTR,.

Tzortzopoulos, P., Sexton, ,. M., \& Cooper, ,. R. (2005). "Process models implementation in the construction industry: a literature synthesis'. Engineering, Construction and Architectural Management, 12(5), 470-86.

Van Winkelen, C. and McKenzie, J. (2007), "An integrated approach to enabling more effective knowledge flows in an organization', in Kazi, A.S., Wohlfart, L. and Wolf, P. (Eds), Hands-On Knowledge Co-Creation and Sharing: Practical Methods and Techniques, Knowledge Board, 169-81.

Wiig, K. (2004). People-focused Knowledge Management: How Effective Decision Making Leads to Corporate Success, . Oxford: Elsevier.

Yun, G., Shin, D., Kim, H., \& Lee, S. (2011). Knowledge-mapping model for construction project organizations. JOURNAL OF KNOWLEDGE MANAGEMENT , 15(3), 528-548. 